\title{
LETTER
}

\section{Thoracic ultrasonography versus chest radiography for detection of pneumothoraces: challenges in deriving and interpreting summary diagnostic accuracy estimates}

\author{
Derek J Roberts ${ }^{1,2^{*}}$, Daniel J Niven ${ }^{2,3}$, Matthew T James ${ }^{2,4}$, Chad G Ball ${ }^{1,5,6}$ and Andrew W Kirkpatrick ${ }^{1,3,6}$
}

See related research by Alrajab et al., http://ccforum.com/content/17/5/R208

\begin{abstract}
Alrajab and colleagues recently conducted a meta-analysis examining the diagnostic accuracy of thoracic ultrasonography (US) or chest radiography (CXR) versus a reference standard of thoracic computed tomography for detection of pneumothoraces [1]. They reported that while the pooled specificity of US (98\%) was similar to CXR (99\%), the pooled sensitivity (79\%) was substantially higher (40\%) [1]. They also found that, although US performance was inferior when conducted on trauma or nonconsecutively sampled patients, it improved when performed by emergency physicians or using a linear probe [1]. We highlight two important issues exemplified.

First, when inter-study threshold variation exists, two novel meta-analytic methods are available that consider the correlation between sensitivity and specificity across studies [2]. Interestingly, using one of these methods (bivariate random-effects models [3]) instead of the classical approach utilized by Alrajab and colleagues [1] may affect some of the inferences drawn from their results. In support of this, only patient type (trauma versus nontrauma), and not whether the study was performed by emergency physicians,
\end{abstract}

on consecutively sampled patients, or using a linear probe, was significantly associated with differences in US performance in univariate meta-regression using bivariate randomeffects models (Table 1 ).

Second, as most patients included in the meta-analysis by Alrajab and colleagues were supine trauma patients [1], the majority of pneumothoraces missed by CXR may have been occult. Occult pneumothoraces are those not seen on initial supine anteroposterior CXR that are subsequently identified on computed tomography [4]. Occult pneumothoraces are associated with a different clinical course and frequently may not require pleural drainage [4]. As tube thoracostomy is not a benign procedure [5], the immediate adoption of US for pneumothorax diagnosis based on the findings of existing diagnostic accuracy metaanalyses, followed by more widespread treatment of occult pneumothoraces, may result in unintended harm. Thus, further research is required to demonstrate that US can differentiate between occult and overt pneumothoraces and provide a net patient benefit before contemplating replacement of CXR with US.

\section{Authors' response}

Saadah Alrajab, Gloria Caldito and Asser M Youssef

We thank Dr Roberts and his colleagues for their interest in our meta-analysis [1]. With regards to the heterogeneity found in our analysis after data synthesis, Borenstein and colleagues [6] suggested the performance of meta-regression

\footnotetext{
* Correspondence: Derek.Roberts01@gmail.com

'Department of Surgery, University of Calgary, Foothills Medical Centre, 1403-29th Street Northwest, Calgary T2N 2 T9, Alberta, Canada ${ }^{2}$ Department of Community Health Sciences, University of Calgary, 3280 Hospital Drive Northwest, Calgary T2N 4Z6, Alberta, Canada Full list of author information is available at the end of the article
}

or subgroup analysis to explain heterogeneity between studies. We utilized both methods. In our supplemental files we provided tables for meta-regression, finding that some factors mentioned were significant, specifically trauma versus nontrauma studies and consecutive versus convenience sampling (eTable3 in [1]). However, in subgroup analyses of all subgroups mentioned (emergency physician-performed US, consecutively sampled patients, and using a linear probe), the confidence intervals were significant. In 
Table 1 Results of subgroup analyses and bivariate meta-regression for identifying covariates to explain heterogeneity in the pooled sensitivity and specificity of chest radiography or ultrasound for detection of pneumothoraces among adults

\begin{tabular}{|c|c|c|c|c|c|c|c|}
\hline \multirow[t]{2}{*}{ Covariate } & \multicolumn{7}{|c|}{ Bivariate random-effects model } \\
\hline & $\begin{array}{l}\text { Pooled sensitivity } \\
(95 \% \mathrm{Cl})^{\mathrm{a}}\end{array}$ & $I^{2}$ statistic & $\begin{array}{l}\text { Sensitivity meta- } \\
\text { regression } P \text { value }\end{array}$ & $\begin{array}{l}\text { Pooled specificity } \\
(95 \% \mathrm{Cl})^{\mathrm{b}}\end{array}$ & $I^{2}$ statistic & $\begin{array}{l}\text { Specificity meta- } \\
\text { regression } P \text { value }\end{array}$ & $\begin{array}{l}\text { Joint } \\
P \text { value }\end{array}$ \\
\hline \multicolumn{8}{|l|}{ Chest radiography } \\
\hline \multicolumn{8}{|l|}{ Patient enrollment } \\
\hline Consecutive & $49 \%$ (30 to $68 \%)$ & $88 \%$ & 0.13 & $100 \%$ (95 to 100\%) & $93 \%$ & 0.01 & 0.33 \\
\hline Nonconsecutive & $33 \%$ (22 to $46 \%)$ & $85 \%$ & & 100\% (98 to 100\%) & $82 \%$ & & \\
\hline \multicolumn{8}{|l|}{ Patient type } \\
\hline Trauma & $27 \%$ (0 to $56 \%)$ & $N A^{d}$ & 0.62 & $98 \%$ (93 to $100 \%)$ & $N A^{d}$ & 0.54 & 0.02 \\
\hline Nontrauma & $40 \%$ (28 to $53 \%)$ & $89 \%$ & & $100 \%$ (99 to 100\%) & & & \\
\hline \multicolumn{8}{|c|}{ Thoracic ultrasonography } \\
\hline \multicolumn{8}{|l|}{ Patient enrollment } \\
\hline Consecutive & $90 \%$ (69 to $97 \%)$ & $96 \%$ & 0.93 & $99 \%$ (97 to $100 \%)$ & $93 \%$ & 0.59 & 0.41 \\
\hline Nonconsecutive & $82 \%$ (67 to $91 \%)$ & $91 \%$ & & $98 \%$ (96 to $99 \%)$ & & & \\
\hline \multicolumn{8}{|l|}{ Patient type } \\
\hline Trauma & $79 \%$ (48 to $100 \%)$ & $N A^{d}$ & 0.65 & $94 \%$ (88 to $100 \%)$ & $N A^{d}$ & $<0.01$ & 0.07 \\
\hline Nontrauma & $87 \%$ (73 to $94 \%)$ & $95 \%$ & & $99 \%$ (98 to $100 \%)$ & $85 \%$ & & \\
\hline \multicolumn{8}{|l|}{ Operator type } \\
\hline Emergency MD & $90 \%$ (76 to $96 \%)$ & $97 \%$ & 0.73 & $99 \%$ (97 to $100 \%$ ) & $88 \%$ & 0.67 & 0.19 \\
\hline Nonemergency MD & $80 \%$ (61 to $91 \%$ ) & $87 \%$ & & 97\% (95 to 99\%) & $79 \%$ & & \\
\hline \multicolumn{8}{|l|}{ Ultrasound probe type } \\
\hline Linear array & $82 \%$ (61 to $93 \%)$ & $94 \%$ & 0.23 & $99 \%$ (96 to $100 \%$ ) & $87 \%$ & 0.29 & 0.68 \\
\hline Nonlinear array & $89 \%$ (72 to $96 \%)$ & $91 \%$ & & 98\% (96 to $99 \%$ ) & $85 \%$ & & \\
\hline
\end{tabular}

$\mathrm{Cl}$, confidence interval; $\mathrm{MD}$, medical doctor or physician. ${ }^{\mathrm{a}} P$ value for hypothesis test comparing pooled sensitivities. ${ }^{\mathrm{b}} P$ value for hypothesis test comparing pooled specificities. ${ }^{c} P$ value for hypothesis test comparing diagnostic accuracy. ${ }^{d}$ Not available due to the inability to estimate secondary to the small number $(n=2)$ of nontrauma studies.

comparison with the previous meta-analyses (which also used similar regression methods), our analysis included more studies, standardized testing on all patients, minimized bias, and provided better explanation to the heterogeneity.

The issue of supine CXR in majority trauma patients was addressed in detail in the discussion section of our paper [1]. We agree that the adoption of US over CXR without taking into consideration the volume of pneumothorax and the patients' clinical status is wrong and may lead to unnecessary and possibly harmful interventions. US can be used instead of CXR to identify the size of incomplete pneumothorax if the clinician can identify the lung point in a supine position $[7,8]$. We suggested further research applied to different clinical settings to evaluate the downstream effects (subsequent tests, procedures, patient outcome and condition-related cost of care) of two testing strategies - one that utilizes US and another for CXR.

Based on current evidence, we believe that US can safely replace CXR in certain clinical circumstances as an initial step to evaluate pneumothorax with a potential for cost saving and reduction in radiation exposure - specifically, when the question is the presence or absence of pneumothorax and no additional information is sought from CXR. An example is a negative US for pneumothorax after post-transbronchial or post-transthoracic lung biopsy eliminates the need for CXR.

Abbreviations

CXR: Chest radiography; US: Ultrasonography.

\section{Competing interests}

AWK received an unrestricted gift of a NanoMaxx ${ }^{\mathrm{TM}}$ Ultrasound Machine from SonoSite, Inc. (Markham, ON, Canada) for research purposes. The remaining authors declare that they have no competing interests.

\section{Authors' contributions}

DJR, DJN, and MTJ were involved with study conception and design. DJR extracted the data for bivariate random-effects meta-analysis while DJR and DJN computed summary diagnostic accuracy estimates and performed bivariate meta-regression. DJR, DJN, MTJ, CGB, and AWK interpreted the results of these analyses. DJR drafted the manuscript, which was critically revised for intellectual content by DJN, MTJ, CGB, and AWK through subsequent revisions. SA composed the manuscript. SA, GC and AMY reviewed the manuscript and data and made suggestions. All authors read the final manuscript and approved it to be submitted for publication. 


\section{Authors' information}

DJR is a Surgery and Clinician Investigator Program Resident who is presently conducting a Doctor of Philosophy (Epidemiology) degree with a thesis on trauma damage control surgery at the University of Calgary. DJN and MTJ are academic critical care/nephrology physicians while CGB and AWK are academic trauma/acute care/hepatopancreaticobilary and trauma/ acute care surgeons at the University of Calgary.

\section{Acknowledgements}

DJR is supported by an Alberta Innovates - Health Solutions Clinician Fellowship Award, a Knowledge Translation Canada Strategic Funding in Health Research Fellowship, and funding from the Canadian Institutes of Health Research and the Clinician Investigator Program at the University of Calgary. These funders had no role in the collection, analysis, or interpretation of the data; in writing of the manuscript; or in the decision to submit the manuscript for publication

\section{Author details}

'Department of Surgery, University of Calgary, Foothills Medical Centre, 1403-29th Street Northwest, Calgary T2N 2 T9, Alberta, Canada. ${ }^{2}$ Department of Community Health Sciences, University of Calgary, 3280 Hospital Drive Northwest, Calgary T2N 4Z6, Alberta, Canada. ${ }^{3}$ Department of Critical Care Medicine, University of Calgary, Foothills Medical Centre, 1403-29th Street Northwest, Calgary T2N 2 T9, Alberta, Canada. ${ }^{4}$ Department of Medicine, University of Calgary, Foothills Medical Centre, 1403-29th Street Northwest, Calgary T2N 2 T9, Alberta, Canada. ${ }^{5}$ Department of Oncology, University of Calgary, Foothills Medical Centre, 1403-29th Street Northwest, Calgary T2N 2 T9, Alberta, Canada. ${ }^{6}$ Regional Trauma Services, University of Calgary, Foothills Medical Centre, 1403-29th Street Northwest, Calgary T2N 2 T9, Alberta, Canada.

\section{Published: 06 Mar 2014}

\section{References}

1. Alrajab S, Youssef A, Akkus N, Caldito G: Pleural ultrasonography versus chest radiography for the diagnosis of pneumothorax: review of the literature and meta-analysis. Crit Care 2013, 17:R208.

2. Leeflang MM, Deeks JJ, Gatsonis C, Bossuyt PM, Cochrane Diagnostic Test Accuracy Working Group: Systematic reviews of diagnostic test accuracy. Ann Intern Med 2008, 149:889-897.

3. Reitsma JB, Glas AS, Rutjes AW, Scholten RJ, Bossuyt PM, Zwinderman AH: Bivariate analysis of sensitivity and specificity produces informative summary measures in diagnostic reviews. J Clin Epidemio/ 2005, 58:982-990.

4. Canadian Trauma Trials Collaborative and the Research Committee of the Trauma Association of Canada, Kirkpatrick AW, Rizoli S, Ouellet JF, Roberts DJ, Sirois M, Ball CG, Xiao ZJ, Tiruta C, Meade M, Trottier V, Zhu G, Chagnon F, Tien $\mathrm{H}$ : Occult pneumothoraces in critical care: a prospective multicenter randomized controlled trial of pleural drainage for mechanically ventilated trauma patients with occult pneumothoraces. I Trauma Acute Care Surg 2013, 74:747-754. discussion 754-755.

5. Ball CG, Lord J, Laupland KB, Gmora S, Mulloy RH, Ng AK, Schieman C, Kirkpatrick AW: Chest tube complications: how well are we training our residents? Can J Surg 2007, 50:450-458.

6. Borenstein M, Hedges LV, Higgins JPT, Rothstein HR: Subgroup analysis and notes on subgroup analysis and meta-regression. In Introduction to Meta-analysis. Chichester: John Wiley \& Sons; 2009:150-186. 205-223.

7. Soldati G, Testa A, Sher S, Pignataro G, La Sala M, Silveri NG: Occult traumatic pneumothorax: diagnostic accuracy of lung ultrasonography in the emergency department. Chest 2008, 133:204-211.

8. Lichtenstein D, Mezière G, Biderman P, Gepner A: The 'lung point': an ultrasound sign specific to pneumothorax. Intensive Care Med 2000, 26:1434-1440.

\section{$10.1186 / \mathrm{cc} 13759$}

Cite this article as: Roberts et al:: Thoracic ultrasonography versus chest radiography for detection of pneumothoraces: challenges in deriving and interpreting summary diagnostic accuracy estimates. Critical Care 2014, 18:416 